\title{
Histopathological Spectrum of Non-Neoplastic Uterine Cervical Lesions in a Tertiary Care Centre
}

\author{
Priyadarshini. D* and Arathi. C.A
}

Department of Pathology, Shridevi Institute of Medical Sciences And Research Hospital, Tumakuru, India

\begin{abstract}
Background: Uterine cervix in our routine hysterectomies and biopsies from gynecological specimens constitutes major portal for nonneoplastic lesions. Routine histopathological study of suspicious cases enhances early detection of these uterine cervical lesions.

Methods: 250 cases of uterine cervical non-neoplastic lesions were evaluated either from hysterectomy or cervical biopsy specimens. The purpose of this study is to analyze and determine the frequency and histomorphological patterns of non-neoplastic cervical lesions at the tertiary care center and to study various metaplasias of the endocervical epithelium. The cervical lesions were subjected to detailed gross and microscopic examination and further classified into various non-neoplastic lesions

Result: Our study showed that $48 \%$ of cases featured chronic nonspecific cervicitis. The commonest encountered endocervical epithelial lesions were chronic polypoidal endocervicitis (20\%) and squamous metaplasia (36\%) and the uncommon lesions included micro glandular adenosis (3.2\%), endocervical glandular hyperplasia (4\%), diffuse laminar endocervical glandular hyperplasia(0.8\%) tunnel clusters $(0.4 \%)$ and mesonephric rests $(0.4 \%)$. A majority of the ectocervical lesions includes Koilocytic changes, exocytosis, Suprabasal bulla and prolapse changes like hyperkeratosis and parakeratosis.

Conclusion: In the present study we emphasized mainly about nonneoplastic uterine cervical lesions among which Chronic non-specific cervicitis is the most confronted lesion in histopathological specimens. However, there are many lesions that appear to be exuberant and can be misdiagnosed to be malignant. On the basis of this, a detailed histomorphological study of the nonneoplastic lesions of the cervix was taken up and further categorized into various lesions which can cause serious morbidities and detailed histopathological study is considered as the gold standard.
\end{abstract}

Keywords: Non-neoplastic, Cervicitis, Endocervix, Histopathology, Hyperplasia

\section{Introduction}

In the gynecological specimens, uterine cervix acts as a gateway to a distinctive array of non-neoplastic as well as neoplastic lesions. These non-neoplastic cervical lesions are most common in the women of reproductive age group. Accordingly, the cervical specimens should be analyzed with utmost care as these lesions can lead to significant morbidity in women.

The majority of the histopathological specimens are from gynecological department and includes predominantly inflammatory and some tumor likes nonneoplastic lesions. Therefore, the histopathological evaluation is of paramount importance in diagnosing nonneoplastic cervical lesions.

In our routine reporting of nonneoplastic lesions acute and chronic inflammatory lesions of infective and noninfective etiology are considered, but the nonneoplastic tumor-like lesions such as cervical tunnel clusters, mesonephric and diffuse laminar hyperplasia, endometriosis, and micro glandular endocervical hyperplasia which simulates neoplasia are not much emphasized, hence identification of these lesions require familiarity in their histopathological features which is a prerequisite for proper management.

Chronic cervicitis is the most common uterine cervical lesion in the reproductive age group occurring between 25 to 55 years of age linked to sexual activity and also in postmenopausal women because of reduction in immunity and hormonal replacement therapy.

\section{Materials and Methods}

This is a prospective study of 250 cases of nonneoplastic cervical lesions. The study includes 250 nonneoplastic cervical lesions which were analyzed from either hysterectomy or cervical biopsy specimens undertaken in the Department of Pathology at Shridevi institute of medical sciences and Research Hospital, Tumakuru.

The hysterectomy specimens were subjected to detailed gross and microscopic examination,

The specimens were fixed, processed and sections were cut from paraffin-embedded blocks and stained with the routine with Hematoxylin and eosin. 
Uterine cervix sections were studied in detail and identified various nonneoplastic lesions and further categorized into inflammatory, metaplasias and epithelial changes.

\section{Results}

Our study includes 250 cases of nonneoplastic cervical lesions categorized into the variety of lesions. The commonest ectocervical lesions are Koilocytic change $(27.2 \%)$ and prolapse changes $(9.6 \%)$ characterized by epidermidization with hyperkeratosis and parakeratosis, with rare cases of exocytosis and Suprabasal bulla.

The most common endocervical lesions are chronic non specific cervicitis $(48 \%)$ followed by squamous metaplasia (36.8\%), chronic papillary endocervicitis (31.2\%), nabothian cyst $(32 \%)$, chronic polypoidal endocervicitis
(20.08\%), few cases of endocervical polyps (7.2\%), endocervical glandular hyperplasia (4\%)microglandular Adenosis (3.2\%), and The rarely reported cases are tubal metaplasia, Follicular cervicitis, Diffuse laminar endocervical hyperplasia, Endometriosis, Cervical tunnel clusters and Mesonephric rests. (Table 1)

The microscopic images shows important histopathological features of each nonneoplastic lesions (Fig 1-6)

The most frequent age group presented with these nonneoplastic cervical lesions are most common in reproductive age between 25 to 50 years and the chief complaints were pain abdomen, abnormal uterine bleeding, white discharge per vagina, uterine prolapse and post coital bleeding.

Table 1: Various categories and percentage of non neoplastic uterine cervical lesions

\begin{tabular}{|c|c|c|c|}
\hline SI No. & Non neoplastic lesions & No of cases /250 & Percentage \\
\hline 1 & Chronic cervicitis & $120 / 250$ & $48 \%$ \\
\hline 2 & Squamous metaplasia & $92 / 250$ & $36.8 \%$ \\
\hline 3 & Nabothian cyst & $80 / 250$ & $32 \%$ \\
\hline 4 & Chronic papillary endocervicitis & $78 / 250$ & $31.2 \%$ \\
\hline 5 & Koilocytic change & $68 / 250$ & $27.2 \%$ \\
\hline 6 & Chronic polypoidal endocervicitis & $52 / 250$ & $20.8 \%$ \\
\hline 7 & Prolapse changes & $24 / 250$ & $9.6 \%$ \\
\hline 8 & Endocervical polyp & $18 / 250$ & $7.2 \%$ \\
\hline 9 & Endocervical glandular hyperplasia & $10 / 250$ & $4 \%$ \\
\hline 10 & Microglandular Adenosis & $8 / 250$ & $3.2 \%$ \\
\hline 11 & Tubal metaplasia & $7 / 250$ & $2.8 \%$ \\
\hline 12 & Intestinal metaplasia (goblet cell metaplasia) & $4 / 250$ & $1.6 \%$ \\
\hline 13 & Follicular cervicitis & $2 / 250$ & $0.8 \%$ \\
\hline 14 & Diffuse laminar endocervical glandular hyperplasia & $2 / 250$ & $0.8 \%$ \\
\hline 15 & Suprabasal bulla & $2 / 250$ & $0.8 \%$ \\
\hline 16 & exocytosis & $2 / 250$ & $0.8 \%$ \\
\hline 17 & Cervical tunnel clusters & $1 / 250$ & $0.4 \%$ \\
\hline 18 & Mesonephric rests & $1 / 250$ & $0.4 \%$ \\
\hline 19 & Endometriosis & $1 / 250$ & $0.4 \%$ \\
\hline
\end{tabular}



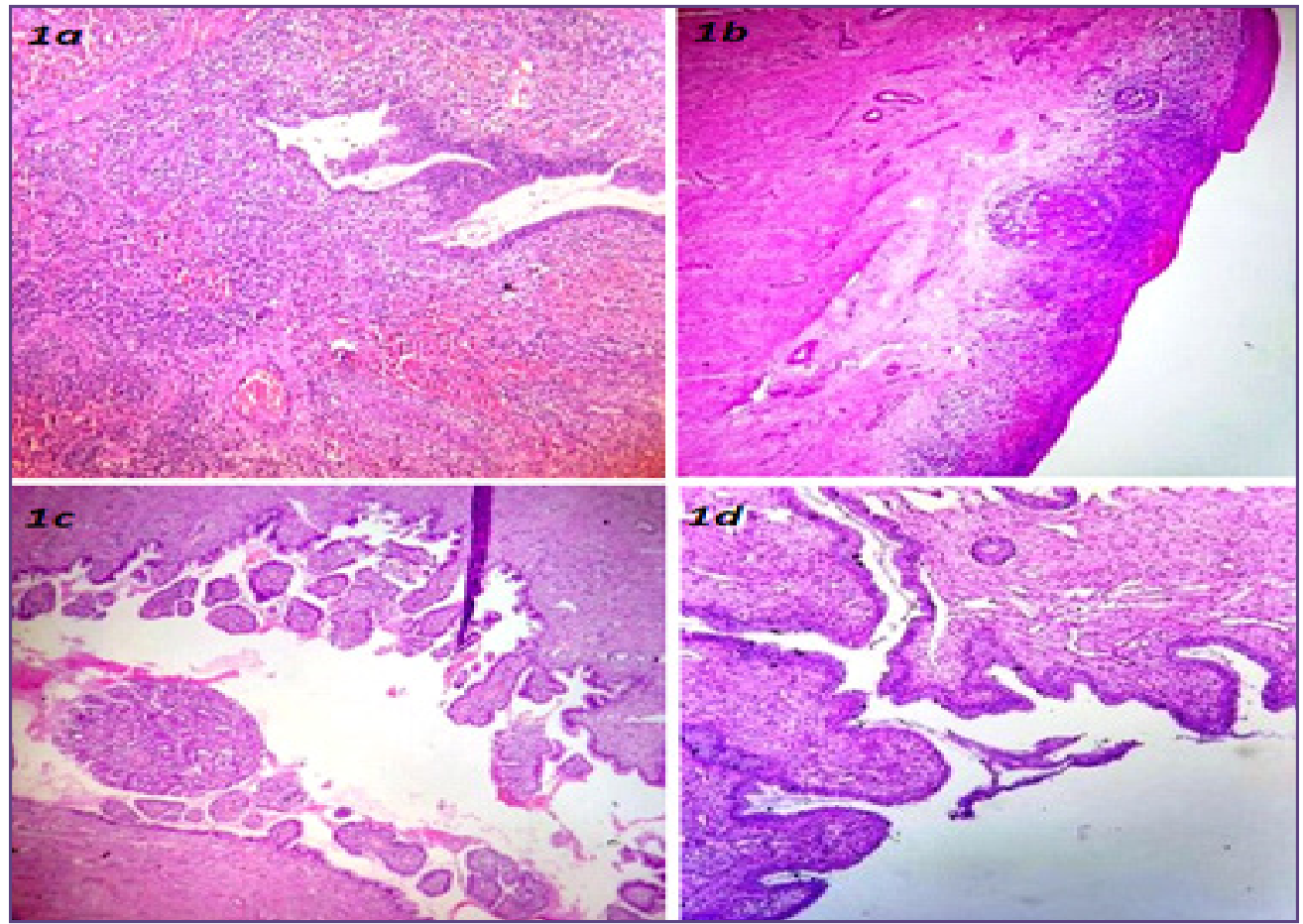

Fig. 1: Photomicrograph showing 1a-Chronic inflammatory cells (H and E 10x). 1b-Follicular cervicitis :Lymphoid follicles(H and E 10x). 1c-Chronic papillary endocervicitis:Papillary infoldings (H and E 10x). 1d-Chronic polypoidal endocervicitis: Polypoidal mucosal folds ( $\mathrm{H}$ and E 10x).

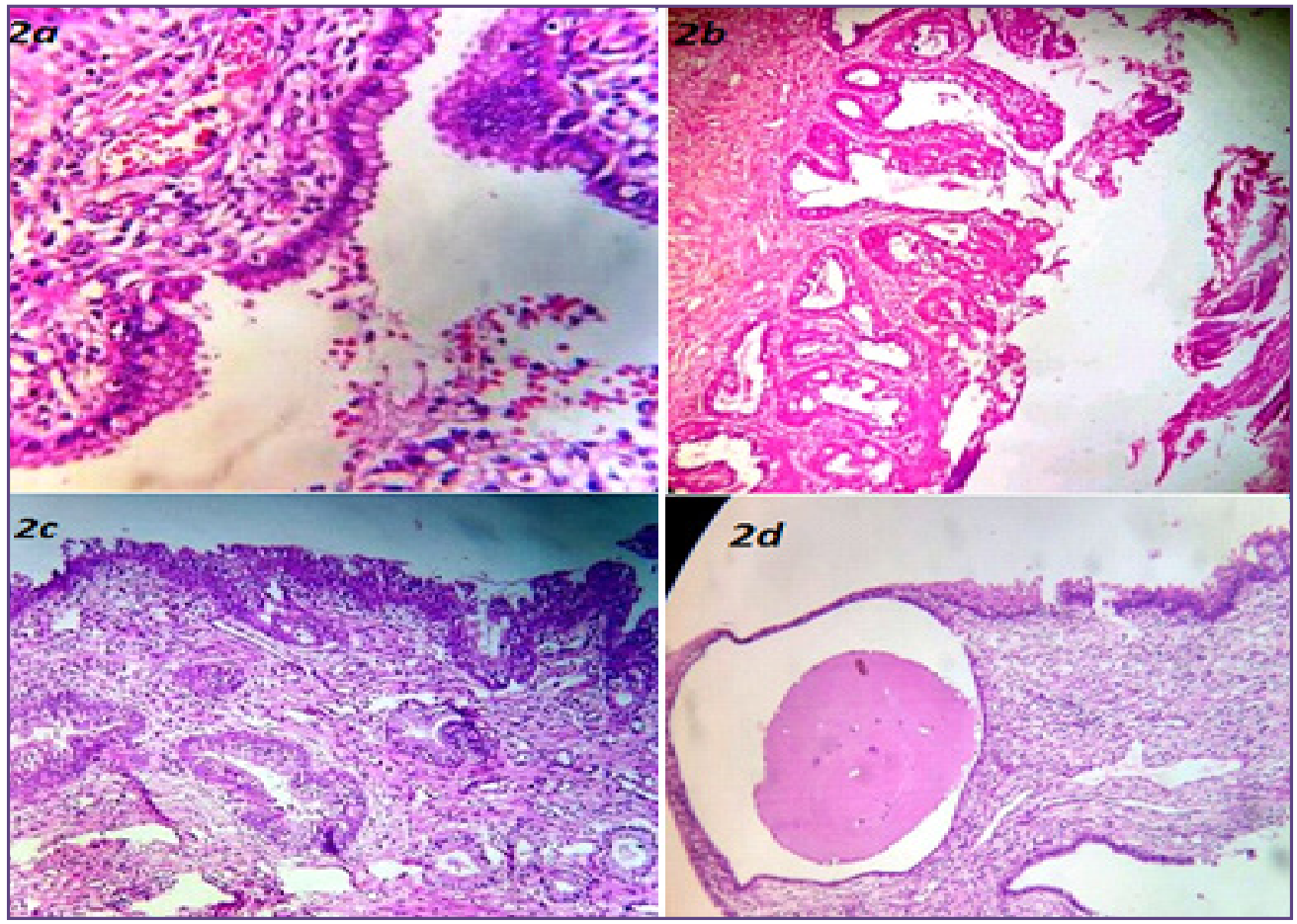

Fig. 2: Photomicrograph showing: 2a-Tubal metaplasia (Hand E 40x). 2b- Goblet cell metaplasia (H \& E 10x). 2c-Squamous metaplasia (H \& E 10x). 2d- Nabothian cyst(H \& E 10x) 


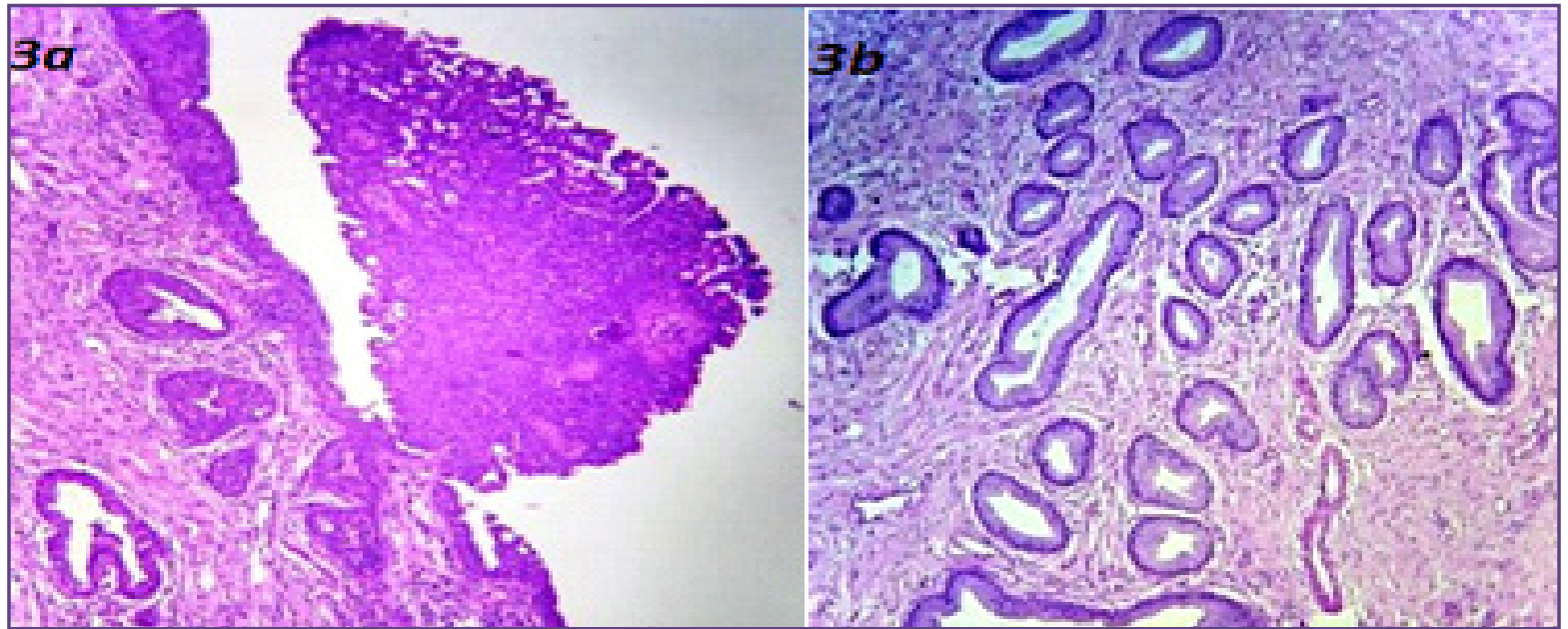

Fig. 3: photomicrograph showing ; 3a-Endocervical polyp (H \& E 10x). 3b-endocervical glandular hyperplasia(H \& E 10x).

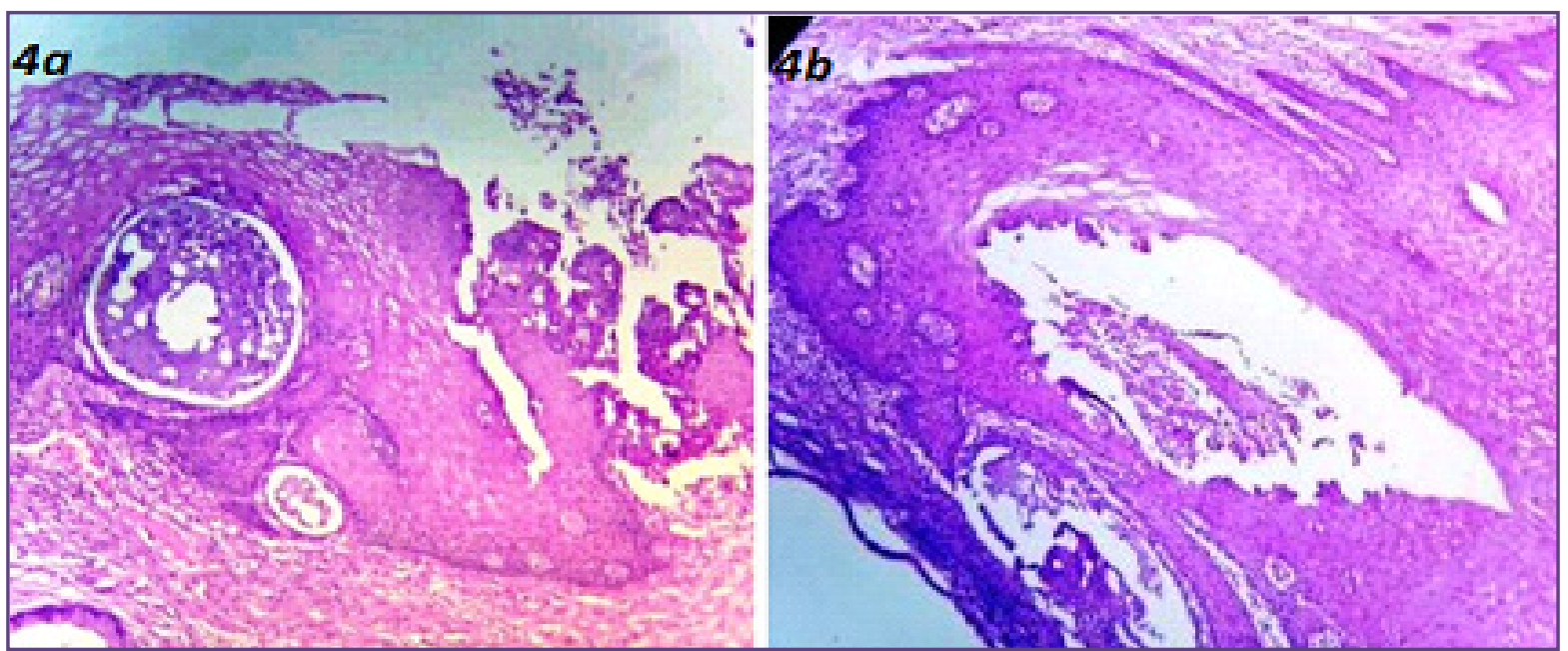

Fig. 4: Photomicrograph showing;4a- Koilocytic change with exocytosis (H \& E 10x). 4b- Suprabasal bulla with cervical prolapse changes (H \& E10x).

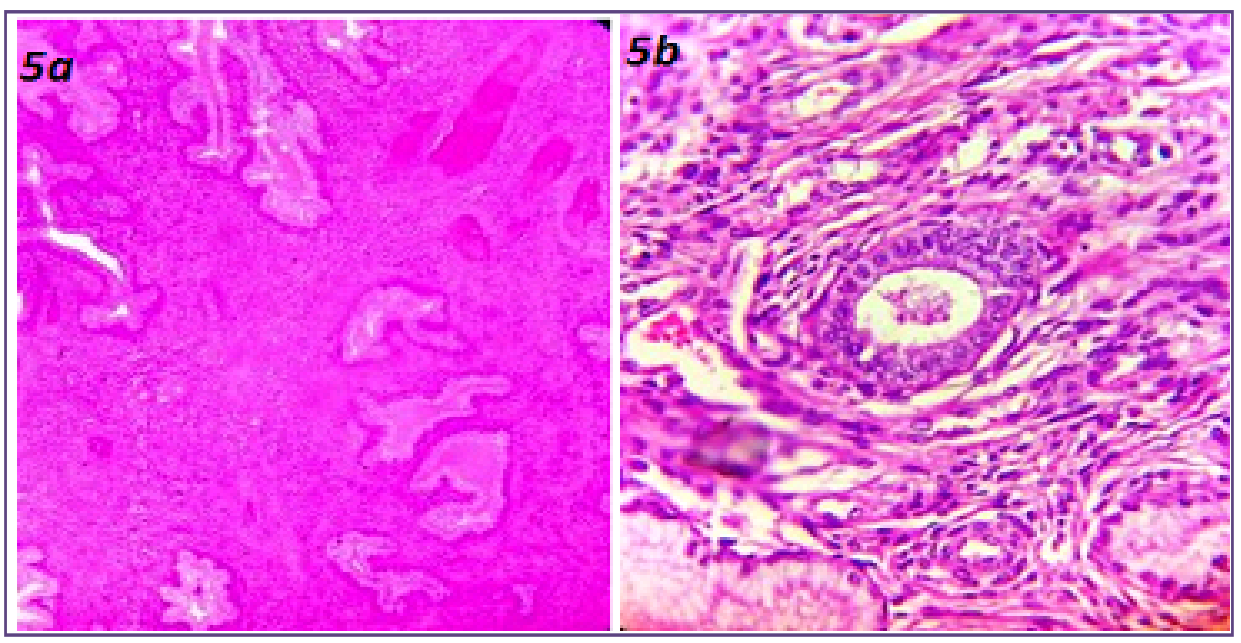

Fig.5: Photomicrograph showing; 5a-Cervical tunnel clusters (H \& E 10x). 5b- Mesonephric rests (H \& E 10x). 


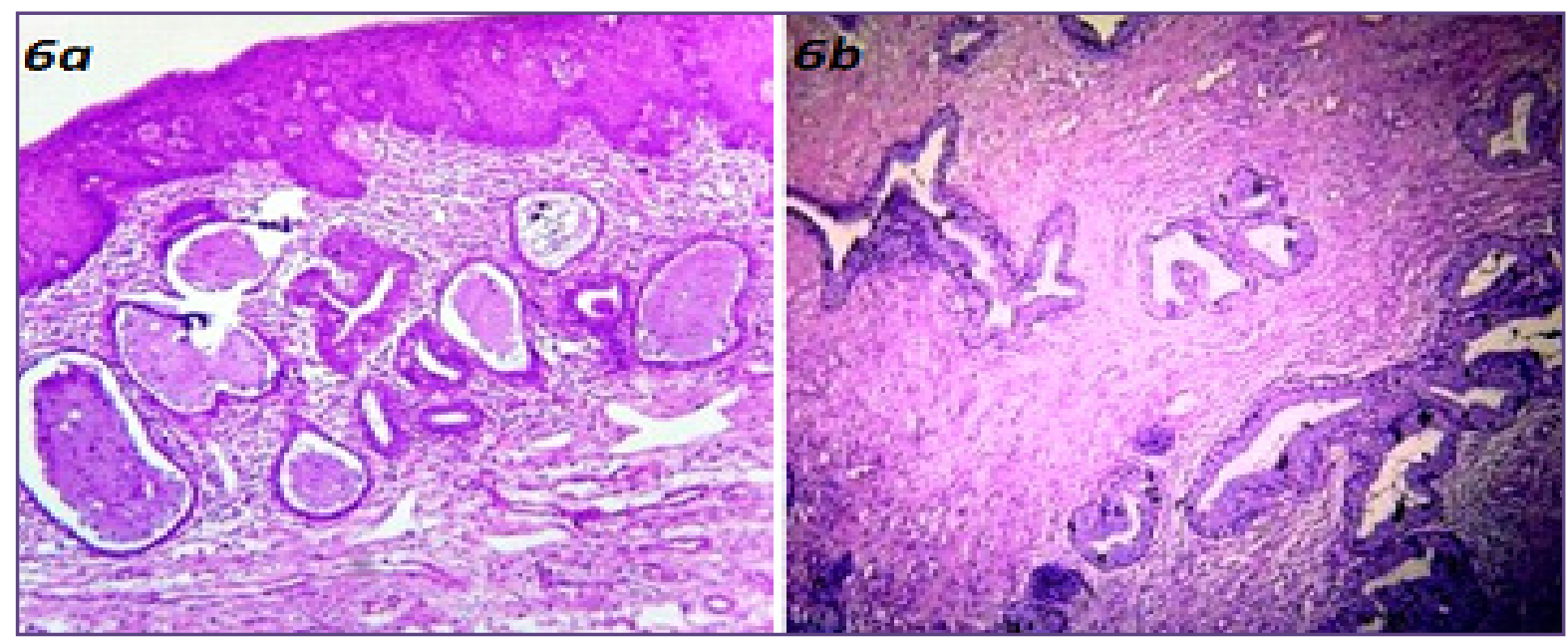

FIG: 6a-Microglandular adenosis (H \& E 10x). 6b-Diffuse laminar endocervical glandular hyperplasia (H \& E 10x).

\section{Discussion}

Uterine cervix forms the major portal for the non-neoplastic lesions in the routine histopathology specimens. There are significant numbers of non-neoplastic lesions, which are of immense importance to the clinician and the pathologist as these lesions are notably overlooked, diagnosis and approach towards these lesions are greatly neglected.

Naveen Kumar B J et.al ${ }^{[1]}$ depicted that there is poor cervical cytology correlation with subsequent cervical biopsy reports. Accordingly, for the diagnosis of nonneoplastic uterine cervical lesions, histopathological examination still remains the gold standard.

Reddy SD et.al ${ }^{[2]}$ described that nonneoplastic lesions of uterine cervix configure bountiful quantum of gynaecological specimens in the histopathological section. The commonest lesion is "chronic cervicitis" displaying chronic inflammatory cells. Our study also reported chronic non specific cervicitis is the most confronted lesion. The most frequent symptom patient presents with non neoplastic cervical lesions are Abnormal Uterine Bleeding, pain abdomen, white discharge per vagina and postcoital bleeding and other non specific chronic inflammatory diseases.

Olutoyin $\mathrm{G}$ et.al ${ }^{[3]}$ reported that $82 \%$ of nonneoplastic lesions of the cervix occur predominantly in sexually active age group and most commonly inflammatory in nature. They may be acute or chronic; each of these can be either infective or non-infective cause. Sexually transmitted diseases, chronic Granulomatous inflammation and viruses especially Human papilloma virus and Herpes simplex virus persistently infect the cervix. Chemical irritants, douching, local trauma and foreign bodies like intrauterine contraceptive devices, pessaries and tampons can cause secondary infections.

Pallipady A et.al ${ }^{[4]}$ stated in their study that Koilocytic change is considered as the histological hallmark of the human papilloma virus infection and was diagnosed in $3.84 \%$ among all the cervical specimens during the study period compared to which our study shows $27.2 \%$ of koilocytosis. Follicular cervicitis was observed in 14 cases, out of which 8 cases were in the 4 th decade of life. We had only 2 cases of follicular cervicitis in the 3 rd decade. Suprabasal bulla with acantholytic squamous cells was rare lesions seen only in 2 cases both of these were associated with severe chronic cervicitis which is almost similar to our study.

Deepa Hatwal et.al ${ }^{[5]}$ reported 315 cases of nonneoplastic lesions of the cervix from Uttarakhand and showed that $85 \%$ were chronic inflammatory lesions implies more for the symptom duration along with heavy chronic inflammatory infiltrate and also stated that cervical squamous metaplasia is a physiological change during puberty, reproductive years, menopause and most commonly encountered during a routine histopathological examination.

Nonneoplastic cervical glandular lesions studied were Nabothian cyst, cervical tunnel clusters, diffuse laminar endocervical glandular hyperplasia, mesonephric rests, micro glandular hyperplasia and various metaplasias.

Nabothian cysts: Cervical gross examination of the cervix revealed multiple mucin-filled cysts which on microscopic examination shows cysts lined by columnar to flattened endocervical-type cells without atypia and mitotic activity. ${ }^{[7]}$

Cervical Tunnel Clusters: Richard J et.al ${ }^{[6]}$ reported in detail about endocervical glandular lesions and described 
that Cervical tunnel clusters are frequently multifocal and are approximately $2 \mathrm{~mm}$ in diameter and can be greater than $4 \mathrm{~cm}$ in aggregate and $1.5 \mathrm{~cm}$ in thickness.

Type A clusters are inconspicuous aggregates of tubules that otherwise resemble the mucosal folds cut in various planes. Type B tunnel clusters are different from usual endocervical glands having complex architecture often composed of dilated or cystic tubules arranged in lobular units. We reported $0.4 \%$ of tunnel clusters.

Diffuse Laminar Endocervical Glandular Hyperplasia: The first case of diffuse laminar endocervical glandular hyperplasia was reported in 1991, which is very rare Pseudoneoplastic endocervical glandular lesion with the typical histologic finding of a diffuse laminar proliferation of tightly packed hyperplastic endocervical glands with sharp demarcation from underlying stroma and no deeper than an inner third of cervical wall from the underlying stroma. This lesion can be confused easily with minimal deviation adenocarcinoma which is characterized by an irregular proliferation of glands deep in the cervix. ${ }^{[11-12]}$

Mesonephric Rests: We reported a single case of mesonephric rests. They also stated that the mesonephric rests may mimic adenocarcinoma and can progress to mesonephric carcinoma. ${ }^{[1]}$

Microglandular Hyperplasia: Microglandularhyperplasia is the more common pseudoneoplastic lesions showing a peculiar and distinctive form of polypoid hyperplasia of the endocervix which mimicks well-differentiated endometrial adenocarcinoma and is also common in young women taking oral contraceptive pills. Microglandular endocervical hyperplasia is frequently associated with endocervical squamous metaplasia, explained due to some commune etiologic factors.

To differentiate between microglandular hyperplasia and clear cell carcinoma is based on architectural and cytological changes like papillary pattern of growing without squamous metaplasia in clear cell carcinoma along with big cells with hobnailing pattern, hyperchromatic nuclei and frequent mitoses. ${ }^{[13-14-15]}$ We reported $3.6 \%$ cases of microglandular hyperplasia.

Squamous Metaplasia: The authentic recognition of squamous metaplasia on histopathology is important and can avoid an unnecessary diagnosis of CIN (cervical intraepithelial neoplasia). Our study reported $36 \%$ of squamous metaplasia compared to $14.9 \%$ mentioned in their study. ${ }^{[5]}$

Tubal Metaplasia: Tubal metaplasia tends to occur more commonly in upper endocervix and composed of ciliated, intercalated (peg), and secretory cells, more characteristically found in the fallopian tube. Adenocarcinoma in situ has to be differentiated from atypical tubal metaplasia due to its degree of atypia in which the glands are lined by similar tubal type cells, but are crowded with larger hyperchromatic and pseudostratified nuclei but mitoses and apoptosis are less when compared to insitu lesions. ${ }^{[20]}$

Endometriosis: Endometriosis, Endocervical hyperplasia, and endocervical polyp are nonneoplastic tumor-like conditions sometimes misinterpreted as neoplastic lesion thus leading to inappropriate and aggressive treatment. Endometriosis presents with excessive vaginal bleeding resulting in severe anemia and its complications. ${ }^{[1-2]} \mathrm{We}$ reported only a single case of cervical endometriosis

\section{Conclusion}

Nonneoplastic uterine cervical lesions are the most common cervical lesions followed by malignancies in the study population. Chronic non-specific cervicitis is most commonly reported followed by papillary endocervicitis and other lesions, seen in reproductive age group presenting with abdominal pain, pelvic inflammatory disease, abnormal uterine bleeding and uterine prolapse. Thus, categorization of the cervical non-neoplastic lesions with their histopathological findings and familiarity are necessary for recognizing the lesions and for better management of the patient and can avoid further morbidity and complications.

\section{Acknowledgements}

We thank our Medical Director Dr. Raman M Hulinaykar, Our beloved Principal Dr. S D Desai and Mr. Arun B R for their constant support and encouragement in completing this research study.

\section{Abbreviations \\ H \& E - Hematoxylin and Eosin}

\section{References}

1. Kumar BJ, Annam V. Clinico-Pathological Study of Non-Neoplastic Lesions of Uterine Cervix with their Histopathological Categorization. International Journal of Science and Research. 2013: 2319-7064.

2. Reddy SD, Rani MS, Rao KS. Clinico-histopathologic study of nonneoplastic uterine cervical lesions. Int J Med Sci Public Health. 2016: 5(8);1536-1539.

3. Olutoyin G, Omoniyi-Esan OG, Osasan SA, Ojo OS. Nonneoplastic diseases of the cervix in Nigeria. A histopathological study. Afr Health Sci 2006:6;76-80.

4. Pallipady A, Illanthody S, Vaidya R, Ahmed Z, Suvarna R, Metkar G. A Clinico-Morphological Spectrum of the Non Neoplastic Lesions of the Uterine Cervix at AJ Hospital, 
Mangalore: Journal of Clinical and Diagnostic Research. 2011:5(3); 546-550.

5. Deepa H, Neha B, Arvind K, Sheela C, Sachan B. Spectrum of Nonneoplastic Lesions of Uterine Cervix in Uttarakhand. National Journal of Laboratory Medicine. 2016;1-5.

6. Richard J, Zaino M.D. Glandular Lesions of the Uterine Cervix: Mod Pathol 2000:13(3);261-274.

7. Jayadeep G, Suman LK, Veena S, Sumit G. Clinicopathological Evaluation of Nonneoplastic and Neoplastic Lesions of Uterine Cervix. Imperial Journal of Interdisciplinary Research (IJIR).2016:2(4).

8. Nwachokor FN, Forae GC. Morphological spectrum of nonneoplastic lesions of the uterine cervix in Warri, Nigeria. Niger J Clin Pract.2013:16(4);429-32.

9. Matos E, Lotia D, Amestoy G, Herrera L, Prince MA, Moreno $J$, et al. Prevalence of human papillomavirus infection among women in Concordia, Argentina: A population based study. Sex Transm Dis.2003;30;593-9.

10. Jyothi V, Manoja V, Reddy KS. A clinicopathological study on cervix.2015:4(1)3;2120-2126

11. Nucci MR. Symposium Part III: Tumor-Like Glandular Lesions of the Uterine Cervix. Int J Gynecol Pathol. 2002: 21(4); 347-359.

12. Louis AD, Thomas CK, Joel CW, Christopher MZ, John CE, Mildred RC et.al. Diffuse Laminar Endocervical Glandular Hyperplasia A Case Report. Int J Gynecol Cancer 2009:19;1091-1093.
13. Florescu M, Simionescu C, Georgescu CV, Marinescu M. Histopathologic aspects in microglandular hyperplasia of endocervix. Morphol-Embryol.2004:181-184

14. Simionescu C, Margaritescu CL, Georgescu CV, Mogoanta L, Marinescu AM. Pseudo-tumoral lesions of the cervix. Rom J Morphol Embryol 2005:4;239-47.

15. Medeiros F, Bell DA. Pseudoneoplastic lesions of the female genital tract. Arch Pathol Lab Med. 2010:134(3);393-403.

16. Younis MT, Iram S, Anwar B, Ewies AA. Women with asymptomatic cervical polyps may not need to see a gynaecologist or have them removed: an observational retrospective study of 1126 cases. Eur J Obstet Gynecol Reprod Biol. 2010: 150(2):190-4.

17. Ozumba BC, Nzegwu MA, Anyikam A. Histological patterns of gynaecological lesions in Enugu, Nigeria. A five year review. Adv Biores.2011;2:132-36.

18. Nigatu B, Gebrehiwot Y, Kiros K, Eregete W. A five year analysis of histopathological results of cervical biopsies examined in a pathology department of a teaching hospital (2003-2007). Ethiop J Reprod Health 2010:4;52-7.

19. Fatima Q, Verma S, Bairwa NK, Gauri LA. Spectrum of Various Lesions in Cervical Biopsies in North West Rajasthan: A Prospective Histopathological Study. Int J Med Res Prof.2017: 3(1); 104-11.

20. Kay J P, Robert A. Current concepts in cervical Pathology. Archives of Pathology \& Laboratory Medicine.2009:133; 729-738.

*Corresponding author:

Dr. Priyadarshini. D. \#108, A Block, Sai Gangotri Apartments, Ullal main road, Opp Bharath Petroleum, Muneshwaranagar, Bengaluru - 560056, INDIA Phone: +91 7829765527

Email: priyadarshinid.arun@gmail.com

Date of Submission : 12.03.2017

Date of Acceptance : 06.04.2017

Financial or other Competing Interests: None.

Date of Publication : 04.07.2017 